\title{
An infinite fraction
}

\author{
Lydia Kang, MD
}

Department of General Internal Medicine, University of Nebraska Medical Center, Omaha, NE, USA.

J Gen Intern Med 25(7):754

DOI: $10.1007 / \mathrm{s} 11606-010-1343-8$

(c) Society of General Internal Medicine 2010

Pressure in the vessels of his lungs-

A push, an incessant crush, a river rising.

Vacuuming becomes a luxurious

Pastime, past time and a moment somewhere

Else, anywhere but here.

I can smell him, he says. My father-

When he was sick and dying he had this scent.

I smell it on me, he weeps. He feels what

Approaches. His wife caresses his back,

A palmed sanctuary to sweep away the knowing.

A sky full of air and facile strength are memorialized

Only a short breath ago, only yesterday.

He cannot stop grasping the air, but to catch it

Is far less easy with what he's got.

And then there is a mind, still

Unmercifully awake to face each bare day,

Each measured inhalation and exhalation

To feed a heart and crowded, unwanted thoughts.

He pushes the vacuum cleaner like it's going to

inhale the future and all the millimeters

Of mercury flying high in those lungs.

I want to tell him that life has a limited allotment

Of terror and grief. Look closely, I want to say. Look at her.

In the absence of dread, in the seconds of

An easy sigh, I see it. An infinite fraction

Of peace.

Corresponding Author: Lydia Kang, MD; Department of General Internal Medicine, University of Nebraska Medical Center, 983331 Nebraska Medical Center, Omaha, NE 68198-3331, USA (e-mail: lkang@unmc.edu).

Published online April 10, 2010 